\title{
A Case Report on Proximal Humerus Fracture and Physiotherapy Rehabilitation
}

\author{
Vaidehi Kannao, Nikita Deshmukh, Shivani Uttamchandani, Pratik Phansopkar* \\ Department of Musculoskeletal Physiotherapy, Ravi Nair Physiotherapy College, Datta \\ Meghe Institute of Medical Sciences, Sawangi Meghe, Wardha, Maharashtra, India. \\ Corresponding author email: drpratik77@gmail.com
}

\section{ABSTRACT}

Six percent of all fractures in the world reflect proximal humerus fractures.(1) The second most common fracture of the upper limb is the proximal humerus fracture, accounting for 45\% of all humeral fractures.Proximal humerus fractures are reported to be quite recurrent in elderly people. The care should focus on functional rehabilitation and management of pain. Intervention modalities include non-operative modalities and osteosynthesis or arthroplasty depending on the case. This is a caseof a farmer who sustained injury to left upper limb due to fall. He complained of pain and swelling and was diagnosed with fracture of proximal left humerus. It was treated with open reduction internal fixation with PHILOS (The Proximal Humeral Internal Locking Osteosynthesis) plating. Patient came back withdischarge and swelling from suture site which suggested infection. Fracture of proximal left humerus with functional limitations. open reduction internal fixation with PHILOS plating followed by physiotherapy rehabilitation. Timely treatment and proper rehabilitation can help to resume functional efficiency of fractured upper limb independently.

KEY WORDS: FRACTURE, PROXIMAL HUMERUS, PHILOS, REHABILITATION, PHYSIOTHERAPY, INFECTION.

\section{INTRODUCTION}

Six percent of all fractures in the world reflect proximal humerus fractures (Schumaier and Grawe, 2018). The proximal humerus fracture is the second most common fracture of the upper limb and accounts for 45\% of all humerus fractures (Narayanan, 2018). It occurs mostly in individuals above 50 years and the incidence increases for ages 60 to 90 years (Khmelnitskaya et al., 2012; Bais et al., 2020). In proximal humeral fractures, the purpose of treatment is to obtain a painless and functional shoulder at the same time. This outcome depends on the patient's age, medical condition, bone quality and aspirations, as well as a clear assessment of the existing techniques of fixation. Common treatment techniquesinclude

Biosc Biotech Res Comm P-ISSN: 0974-6455 E-ISSN: 2321-4007

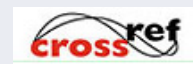

Identifiers and Pagination

Year: 2021 Vol: 14 No (6) Special Issue

Pages: $120-123$

This is an open access article under Creative

DOI: $h t t p: / / d x . d o i . o r g / 10.21786 / b b r c / 14.6 .28$
Commons License Attribn 4.0 Intl (CC-BY).
Open reduction and internal fixation, hemiarthroplasty, pinning, screw osteosynthesis and use of intramedullary nails. Possible risks of surgery for humeral fractures are loosening or implant failure and non-union.

In these fractures, there is no cure that can be the gold standard yet. The "AO/ASIF group" developed the PHILOS (The Proximal Humeral Internal Locking Osteosynthesis) plate to reduce the post treatment complications in humerus fracture. This is an internal fixation system that enables angled stabilization with multiple interlocking screws.A few prospective studies reported the effects of this procedure on the complications associated with the treatment (Bansal et al., 2015; Rubin et al., 2002; Wane et al., 2020).

Patient information: A 75 years old male, a retired farmer, was brought to AVBRHospital, Sawangi Meghe, Wardha, after two days with an alleged history of slip and fall at home with a sustained injury to left upper limb with no loss of consciousness, bleeding or vomiting. He came with complains of pain and swelling over left arm since the fall. He was diagnosed with proximal left humerus fracture. It was stabilized after four days using open reduction 
internal fixation with PHILOS plating. He revisited the hospital after discharge with complains of discharge and swelling from suture site in the last five days with no history of fever or constitutional symptoms. Which suggested that it was infected. Detriment was done for the infection. He was referred to physiotherapy with pain on suture site, reduced range of motion and weakness of left upper limb for further management.

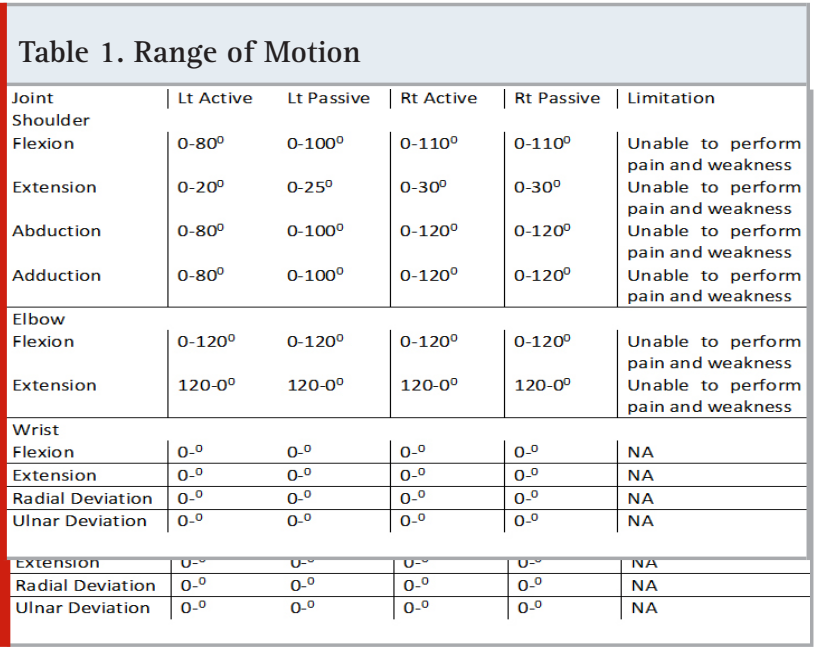

Table 2. Isometric Strength

\begin{tabular}{l|l|l|}
\hline Muscles & Left & Right \\
\hline Shoulder & Weak and painful & Strong and painless \\
\hline Flexors & Weak and painful & Strong and painless \\
\hline Extensors & Weak and painful & Strong and painless \\
\hline Abductors & Weak and painful & Strong and painless \\
\hline Adductors & \\
\hline Elbow & Strong and painless & Strong and painless \\
\hline Flexors & Strong and painless & Strong and painless \\
\hline Extensors & & \\
\hline Wrist & Strong and painless & Strong and painless \\
\hline Plantar Flexors & Strong and painless & Strong and painless \\
\hline Doris Flexors & Strong and painless & Strong and painless \\
\hline Invertors \\
Evertors & Strong and painless & Strong and painless \\
\hline
\end{tabular}

\begin{tabular}{|c|c|}
\hline $\begin{array}{l}\text { Weeks since } \\
\text { injury }\end{array}$ & Rehabilitation plan \\
\hline $0-3$ weeks & $\begin{array}{l}\text { - Wear your sling all the time - even in bed at night. } \\
\text { - Remove the sling for personal hygiene and exercises every day. } \\
\text { - Start your exercises straight away, ideally with in the first } 72 \text { hours }\end{array}$ \\
\hline 3-6 weeks & $\begin{array}{l}\text { - Continue to wear the sling. } \\
\text { - Start the Phase } 2 \text { exercises. } \\
\text { - Do not lift your arm above shoulder height or do any heavy lifting. }\end{array}$ \\
\hline 6 - 12 weeks & $\begin{array}{l}\text { - Begin normal light activities with the arm and shoulder. } \\
\text { - Increase your movement using the Phase } 3 \text { exercises. } \\
\text { - Heavy tasks may still cause some discomfort and swelling. } \\
\text { - Start to lift your arm overhead if possible. }\end{array}$ \\
\hline
\end{tabular}

\section{Clinical findings}

Medical management: He visited AVBRH with a sustained injury to left upper limb with no loss of consciousness, bleeding or vomiting. He was diagnosed with proximal left humerus fracture. It was stabilized after four days using open reduction internal fixation with PHILOS plating. After that he revisited as there was some infection.

\section{Physiotherapy management:-}

Post-Operative: The short-term goals included prevention of respiratory complications, reducing pain and oedema. Special focus was given on maintaining and increasing joint range of motion and strength to promote early mobilization. The long-term goals were to promote independent activities, to promote mobility, independent $\mathrm{ADL}$ activities and ergonomics.

\section{For pain relief:-}

Cold packs: Cold packs were used for short term pain relief by applying to the sore area for up to 15 minutes, every few hours ensuring that the ice had no direct contact with the skin.

Rest: Rest was ensured so that shoulder does not become stiff and will help in the healing process.

\section{Exercises: \\ PHASE 1:-}

Passive exercises werestarted as soon as pain permitted. Passive movement to shoulder joint should be started within the painfree range of motion as soon as the pain permit. Gentle range of motion exercises of the neck, elbow, wrist, and hand were started to prevent immobility and secondary complications. Gripping exercises were started. Modalities such as heat and ice for pain control were given. Splint/Sling as direct Cardiovascular conditioning was done. Initially exercises were done 4 to 5 times a day.

\section{PHASE 2:-}

After 3 weeks active assisted exercises are started.Active assisted Shoulder flexion, abduction, external rotation were started.Either therapist can assist or use your other hand to lift your arm up in front.Further patient was progressed to short-range PNF patterns.After that Active Assisted ROM activities were progressed to AROM as tolerated, without compensated movement.

\section{PHASE 3:-}

When full range of movement was regained during the above exercises without pain we started to do the exercises without the support. Active Forward flexion,active abduction and active external rotation were promoted. Exercises like finger ladder pulleys were started.Strengthening was started with minimum weights. Further functional training was provided for maintenance and to increase functional strength.We encouraged the use of handrails, assistive devices and proper shoes at home.

\section{DISCUSSION}

Least number of cases have been reported in literature of proximal humeral fracture. Many of the cases which are reported involves high force or high velocity injuries. In previously reported case, injury was caused by slip and fall at home with a sustained injury to left upper limb, he came with complains of pain and swelling over left arm since the fall. He was diagnosed with proximal left humerus fracture. It was stabilized after four days 
using open reduction internal fixation with PHILOS plating, then he revisited with complains of discharge and swelling from suture site in the last five days with no history of fever or constitutional symptoms. This suggested that there was infection and was further referred to physiotherapy. Rehabilitation objectives were formulated with regards to reduced range of motion and weakness of left limb beginning from low intensity exercises to gradual strengthening (Wane et al., 2020). All the exercises were done three times a day of 10 sets each. With the help of rehabilitation programme, he was able to resume his ADLs independently.

A number of Studies on shoulder pain and joint morphology diagnostics and treatment were reviewed (Meshram et al., 2020; Saoji et al., 2020; Singh et al., 2019; Deshpande et al., 2018). Also a few studies on hand fractures were reviewed (Reddy and Dhaniwala, 2019; Burhani and Naqvi, 2020; Mundada et al., 2017; Saoji et al., 2013; Saoji et al., 2020) Several authors has proposed a specific posture which namely includes Flexed elbow with little abduction of shoulder. Whether fracture or dislocation occur subsequently or simultaneously is debated. Some authors proposed that injuries which involve high velocity traumas, results in simultaneous injuries. Others has postulated that Initial dislocation may be due to indirect forces. In our case, an 75 years old male, a retired farmersuffered slip and fall at home with sustained injury to left upper limb.

Court-Brown in a study of proximal humerus fractures has demonstrated that 49 percent of the proximal humerus fracture were classified as Neer's Type 1 fractures which represents minimal displacement of fractures regardless of number of fragments. They also found that 28 percent of fractures were classified in two part as surgical neck fractures and 9 percent as three part fracture with surgical neck and greater tuberosity fractures. They even pointed that nearby 90 percent of proximal humerus fractures can be classified in these categories.

\section{CONCLUSION}

In this case report a old male, a retired farmer with proximal left humerus fracture and further had infection. The recovery program consisted of a target-based therapy program that decreased postoperative pain, increased range of motion and enhanced patient responsiveness. He was able to resume daily living activities (ADLs) voluntarily with the help of regular rehabilitation.

Ethical Clearance: The institution Ethics committee clearance is obtained.

\section{Conflict of interest: Nil.}

\section{Funding Support: None.}

\section{REFERENCES}

Bais, A., Bawiskar, D., Naqvi, W.M., Sahu A. 2020. A case study on the impact of physiotherapy on unilateral foot drop after lumbar fusion and discectomy.

Burhani, T. and Naqvi, W.M., 2020. Impact Of Immersive Virtual Reality-Based Rehabilitation On Functional Independence And Health Related Quality Of Life After Distal Radius Fracture: A Study Protocol For A Single Blinded Randomized Control Trial. Journal of Critical Reviews, 7(9), pp.559-563.

Deshpande, S.V., Phatak, S.V., Marfani, G.B., Gupta, N.A., Daga, S.S. and Samad, S.S., 2018. Sonographic evaluation of painful shoulder and its comparison with clinical diagnosis. Journal of Datta Meghe Institute of Medical Sciences University, 13(1), p.12.

Khmelnitskaya, E., Lamont, L.E., Taylor, S.A., Lorich, D.G., Dines, D.M. and Dines, J.S., 2012. Evaluation and management of proximal humerus fractures. Advances in orthopedics, 2012.

Latchoumi, T.P., Ezhilarasi, T.P. and Balamurugan, K., 2019. Bio-inspired weighed quantum particle swarm optimization and smooth support vector machine ensembles for identification of abnormalities in medical data. SN Applied Sciences, 1(10), pp.1-10.

Meshram, P., Pawaskar, A. and Kekatpure, A., 2020. 3D CT scan-based study of glenoid morphology in Indian population: Clinical relevance in design of reverse total shoulder arthroplasty. Journal of Clinical Orthopaedics and Trauma, 11, pp.S604-S609.

Mundada, G., Khan, S.M., Singhania, S.K., Gupta, V., Singh, P.K. and Khan, S., 2017. Type-I monteggia with ipsilateral fracture of distal radius epiphyseal injury: A rare case report. Annals of African medicine, 16(1), p.30.

Narayanan, V. L., \&t Balasubramanian, N. (2018). Complex Proximal Humeral Fracture Fixation with PHILOS Plate using Minimal Invasive Percutaneous Plate Osteosynthesis (MIPPO) Technique: A Series of 30 Patients. Malaysian orthopaedic journal, 12(2), 20.

Reddy, S. and Dhaniwala, N., 2019. Diaphyseal fractures in pediatric age group in rural area: A demographic study. Journal of Datta Meghe Institute of Medical Sciences University, 14(3), p.189.

Rubin, B.D. and Kibler, W.B., 2002. Fundamental principles of shoulder rehabilitation: conservative to postoperative management. Arthroscopy, 18(9), pp.2939.

Saoji, A., Saoji, S., Patil, A., Dwidhmuthe, S. and Shrivastava, S., 2013. Total Elbow Arthroplasty Using Bakshi's Floppy Hinge Prosthesis For Gct Of Lower End Humerus'-A Case Report. Journal of Evolution of Medical and Dental Sciences, 2(32), pp.5980-5984.

Saoji, K., Mohit D., Gajanan, P., Aditya, K., Amit, S. 2020. Infected Non Union in an Operated Compound Fracture of Shaft of Humerus: A Case Report. Medical 
Science, 24(105). pp.3215-21.

Saoji, K.K., Gawande, V. and Dulani, R., 2020. A Comparative study of Disability and Pain Assessment by Shoulder Pain and Disability Index (SPADI) Score in Patients of Adhesive Capsulitis Treated by Hydrodilatation with and without Corticosteroids. Int J Cur Res Rev| Vol, 12(14).

Schumaier, A., Grawe, B. 2018. Proximal Humerus Fractures: Evaluation and Management in the Elderly Patient. Geriatr Orthop Surg Rehabil.

Singh, R. and Singam, A., 2019. Comparison between
Supraclavicular and Interscalene Brachial Plexus Block in Patients Undergoing Shoulder Surgery. Journal of Datta Meghe Institute of Medical Sciences University, 14(3), p.175.

Sohal, H.S. and Boparai, R.S., 2015. PHILOS plate in Proximal Humerus Fracture-its functional outcome and complications. International Journal of Orthopaedics, 2(3), pp.317-322.

Wane, M., Naqvi, W.M., Vaidya, L. and Kumar, K., 2020. Kinesiophobia in a Patient With Postoperative Midshaft Fracture: A Case Report of Its Impact on Rehabilitation in a 16-Year-Old Girl. Cureus, 12(11). 